\title{
Emergent needle decompression for tension pneumothorax resulting in life threatening intercostal artery injury
}

\author{
John David Gatz ${ }^{1 *}$,Thomas Grissom ${ }^{1}$ and Ravi Chauhan ${ }^{2}$ \\ ${ }^{1} \mathrm{R}$ Adams Cowley Shock Trauma Center, University of Maryland School of Medicine, Baltimore, Maryland \\ ${ }^{2}$ Defence Medical Services, Camberley, United Kingdom
}

\begin{abstract}
Traumatic tension pneumothorax is a life-threatening injury encountered in pre-hospital trauma patients. Decompression with needle thoracostomy is a technique that can reverse this condition. No intercostal artery injuries from needle decompression (ND) have previously been reported. A 28 -year-old man presented with hemorrhagic shock from multiple stab wounds and concern for tension pneumothorax treated with ND in the pre-hospital setting. Despite embolization of the patient's initial arterial injuries he developed life-threatening hemothorax. Thoracotomy revealed intercostal artery laceration in the region of his ND. ND remains a critical life-saving procedure in tension pneumothorax, but proper technique and site selection is required to minimize complications.
\end{abstract}

\section{Introduction}

Trauma is the leading cause of death for Americans aged between 1-46 years of age and the third leading cause of death in the United States overall [1]. It is the leading cause of mortality globally [2]. Traumatic injuries can range from minor isolated wounds to complex injuries involving multiple organ systems. All trauma patients require a systematic approach to management in order to maximize outcomes and reduce the risk of undiscovered injuries.

A clear, simple, and organized approach is needed when managing a severely injured patient. The assessment disseminated in Advanced Trauma Life Support ${ }^{\mathrm{mm}}$ (ATLS $^{\mathrm{rm}}$ ) provides such an approach [3]. The primary and secondary surveys allow rapid identification of potentially reversible life-threatening injuries in the pre-hospital or in-hospital setting. Identification and treatment can mean the difference between life and death. Such injuries include airway obstruction, tension pneumothorax, open pneumothorax, massive hemothorax, flail chest and cardiac tamponade. The procedures to manage these injuries, however, can be fraught with complications.

We present the first case of iatrogenic intercostal artery (ICA) injury resulting in life-threatening massive hemothorax from emergent needle decompression (ND) - a lethal injury as a consequence of a life-saving intervention. We briefly review the literature surrounding vascular injuries and discuss some of the alternative options for management of tension pneumothorax and why this case may have presented in a delayed manner.

\section{Case report}

A 28-year-old male with no past medical history presented by ambulance after suffering multiple stab wounds. EMS reported concern for tension pneumothorax prior to arrival and performed field needle decompression of the left anterior chest wall. Due to inability to obtain vascular access, an intraosseous needle was placed by EMS in the right humeral head. At the time of presentation, he was afebrile (36.1 C), with blood pressure $72 / 40 \mathrm{~mm} \mathrm{Hg}$, heart rate 108 beats/min, respiratory rate
$22 \mathrm{breath} / \mathrm{min}$, and oxygen saturation $100 \%$ while on supplemental oxygen at $15 \mathrm{~L} / \mathrm{min}$ via non-rebreather mask. Auscultation revealed tachycardic normal heart sounds and bilateral breath sounds. Abdominal examination was soft. The patient had four stab wounds including three superficial wounds present on the right shoulder, left upper paravertebral back, and left middle paravertebral back. A deep stab wound to the left lateral upper back was continuously bleeding despite manual pressure by EMS.

Pertinent laboratory findings included hemoglobin $10.2 \mathrm{~g} / \mathrm{L}$, platelets $192 \mathrm{~K} / \mathrm{mcL}$. Potassium $2.5 \mathrm{mmol} / \mathrm{L}$, bicarbonate $16 \mathrm{mmol} / \mathrm{L}$, lactate $7.9 \mathrm{mmol} / \mathrm{L}$, INR 1.4, TEG clotting time $5.2 \mathrm{~min}$.

The prominent left lateral upper back wound continued to bleed despite packing with sterile gauze and manual pressure at bedside. Due to inability to obtain large bore peripheral access a central venous catheter was placed in the right subclavian for administration of blood products. The patient was intubated due to waxing mental status and repeated non-bloody emesis. Bedside chest radiograph after intubation showed right-sided pneumothorax (suspected iatrogenic from attempted subclavian line placement) (Figure 1). Computed tomography angiography (CTA) confirmed active hemorrhage from branches of the patient's left axillary artery (Figure 2A/2B). The patient was taken emergently to the operating room for angiography.

Angiography confirmed active hemorrhage from branches of the subscapular artery (Figure 3). Selective catheterization and coil embolization of the circumflex scapular artery successfully stopped all further extravasation from that site. The patient then underwent closure of his stab wounds. Post-operatively he developed hemodynamic instability in the Intensive Care Unit and was found to have massive left hemothorax (Figure 4). Tube thoracostomy immediately

${ }^{\star}$ Correspondence to: Ravi Chauhan, Defence Medical Services, Camberley, United Kingdom, E-mail: ravi.chauhan@me.com

Received: April 20, 2018; Accepted: May 17, 2018; Published: May 24, 2018 
drained approximately three liters of blood. The patient remained hemodynamically labile despite ongoing transfusions.

The patient returned to the operating room for a 4th interspace anterolateral thoracotomy. An additional 2 liters of blood was evacuated, and he was found to have arterial hemorrhage coming from the third intercostal space of the anterior chest. There was no evidence

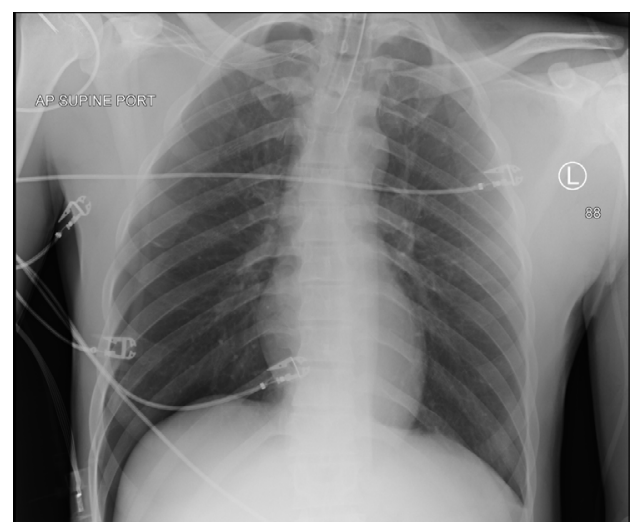

Figure 1: Radiograph shortly after intubation shows right-sided pneumothorax and no significant intrathoracic bleeding
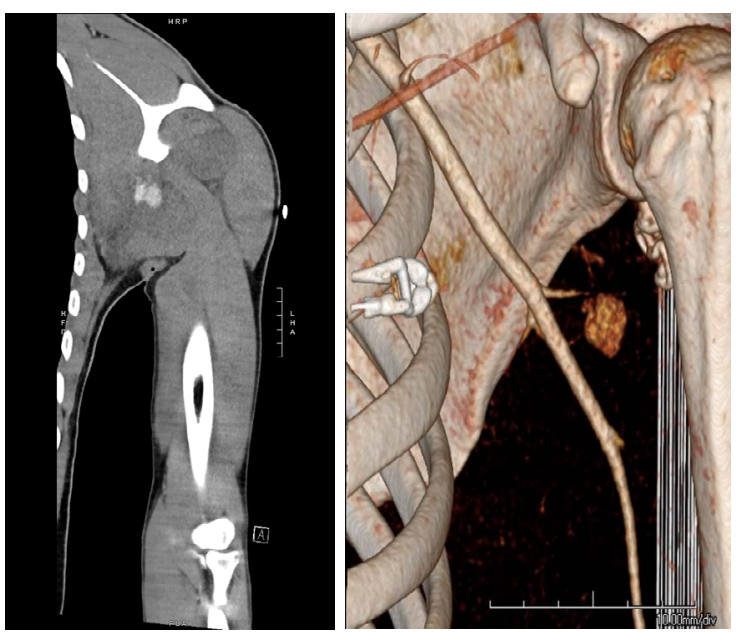

Figure 2: A) CTA showing extravasation from left circumflex scapular artery B) 3D rendering of extravasation site

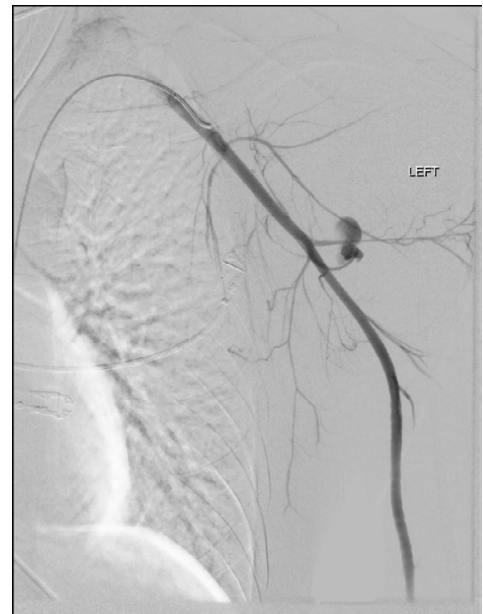

Figure 3: Angiography with brisk bleeding from left circumflex scapular artery

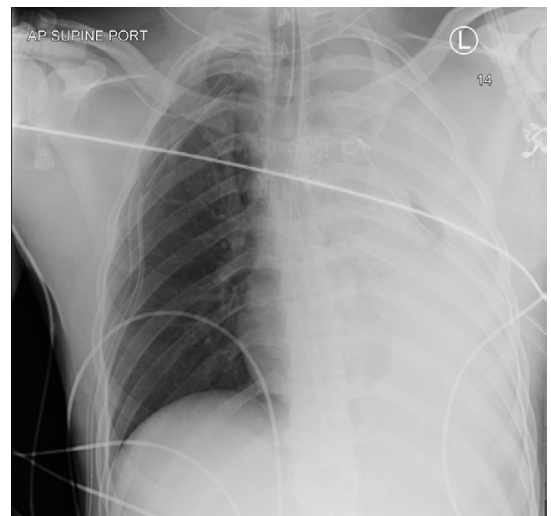

Figure 4: ICU radiograph after coiling of left circumflex scapular artery.

of stab injury in this area other than the patient's known pre-hospital needle decompression. Hemorrhage was successfully controlled after ligation of the medial and lateral components of the bleeding ICA. The patient's hemodynamics stabilized following the procedure and he was discharged one week later.

\section{Discussion}

Needle decompression is an exceptional but potentially lifesaving intervention in trauma patients with a tension pneumothorax. According to trauma guidelines [3], a needle or venous catheter should be inserted in the second intercostal space, mid-clavicular line (2ICS MCL). Injury to the vascular structures is a rare but potentially lifethreatening complication of all pleural interventions, especially in elderly populations. Pleural hemorrhage is reported to occur in up to $2 \%$ of thoracocenteses, up to $13 \%$ of implantable [4,5] cardioverterdefibrillator insertions and up to $4 \%$ of thoracoscopies [6]. However, our literature review did not identify any reports of ICA injury from emergent needle decompression in trauma. Rawlins et al reported 3 non-traumatic cases of tension pneumothoraces and life-threatening hemorrhage after decompression; however, they were unable to isolate the structures involved and ultimately implicated the subclavian and the lung as sources in 2 out of their 3 cases [7]. Yacavone et al were unable to produce any data regarding the rate of ICA injury during thoracentesis from their review but hypothesized that it was likely $<1 \%$. Hemothorax, also on their list of complications, was documented as $<1 \%$ [5]. Injuries to other vascular structures including the pulmonary artery have been documented from emergent decompression [8].

The 2ICS MCL used in this case is the traditional anatomical site of ND for tension pneumothorax. Numerous studies have recently questioned if the chest wall thickness at this site prevents traditional needle lengths $(5 \mathrm{~cm})$ from reaching the pleural space [9-19]. Alternative sites have been recommended and reviewed, including the $4^{\text {th }} / 5^{\text {th }}$ ICS at the anterior axillary line (AAL) and the 4th/5th ICS mid axillary line (MAL). A systematic review and meta-analysis by Laan et al., evaluated differences in the wall thickness between the MCL $(4.3 \mathrm{~cm}$, $95 \%$ CI $3.9-4.7 \mathrm{~cm})$, MAL $(4.0 \mathrm{~cm}, 95 \%$ CI $2.9-5.1 \mathrm{~cm})$, and AAL $(3.4 \mathrm{~cm}$, $95 \%$ CI $2.8-4.0 \mathrm{~cm})$. This corresponded to estimated failure rates with a traditional $5 \mathrm{~cm}$ angiocatheter of 38\% (95\% CI 24-54\%), 31\% (95\% CI $10-64 \%)$, and $13 \%$ (95\% CI 8-22\%) respectively. Inaba et al compared, using CT imaging, the distance the needle travelled in the ICS2-MCL and the 5thICS AAL and showed that ND would be expected to fail in $42.5 \%$ of cases at the 2ICS MCL compared with $16.7 \%$ at the 5 ICS AAL [20]. Kaserer et al documented an even higher failure of ND 
in prehospital patients, more than $80 \%$, postulating inadequate ratio between chest wall thickness and catheter length as one reason [21]. Such high failure rates may partially explain why recent analysis of two large trauma databases showed no mortality benefit from prehospital ND in traumatic cardiac arrest [22].

The comparatively smaller chest wall thickness makes the axillary approach appealing and is now advocated by the British Thoracic Society as an alternative site [23]. The authors of the Tactical Combat Casualty Care Course conducted their own study and consequently revised their guideline after showing the viability of the lateral approach as an acceptable alternative [24].

The use of longer needles has also been proposed. Chang et al performed a retrospective review of CT scans of trauma patients and found that theoretical use of an $8 \mathrm{~cm}$ angiocatheter would overcome the majority of differences in chest wall thickness at these two sites [25]. This was not without risk, however, as it significantly increased the ability to reach underlying vital structures (especially the left ventricle from aleft lateral approach). Besides increased risk of injury to other structures, one study of simulated needle thoracostomies in porcine model raised concern of increased kinking and occlusion in lateral approaches [26].

Regardless of needle site or length, the basic anatomy of the intercostal vessels is essential (Figure 5). These vessels and the intercostal nerve are generally protected by the inferior groove of each rib. The insertion of any intrathoracic needle should be placed just superior to lower rib defining the intercostal space of interest and directed perpendicularly. This minimizes the chance of injuring these intercostal structures.

Consequently, it is essential to consider the risk-benefit ratio of decompression at any site. It has been postulated that in spontaneously breathing patients, the rate of progression of pneumothorax may be less rapid. In the absence of hemodynamic instability or severe respiratory distress, the proper approach may be to carefully monitor the patient and transfer to the appropriate facility were diagnosis can be confirmed and managed [27].

Additionally, unique to this case is the delayed presentation. The patient had a short transit time with EMS and experienced significant blood loss prior to arrival (as evidenced by his hypotension, tachycardia, cool extremities, and tenuous mental status). The degree of blood loss from his initial arterial injury appears to have delayed the presentation of this second arterial injury until he received adequate intervention

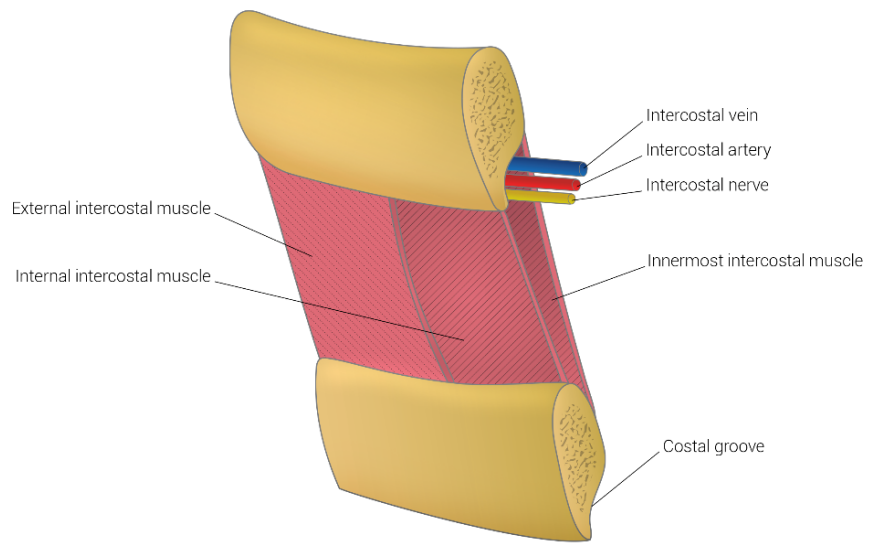

Figure 5: Anatomy of intercostal structures and intravascular repletion of blood products. We postulate that the injured branches of the subscapular artery provided the "path of least resistance" to blood flow. However, upon embolization flow was redirected to the ICA. His clinical course underscores the necessity of re-examination for additional injuries after initial resuscitation.

This case highlights the fact that emergent needle decompression is not without risk. Providers, especially in the prehospital environment, should judiciously reserve this procedure for unstable patients. Effort should be made to select the anatomic sites with the greatest likelihood of success - including consideration of alternative sites. Care should always be made at all sites to insert just superior to the rib to minimize chance of injury to intercostal structures.

\section{References}

1. http://www.nationaltraumainstitute.org/home/trauma_statistics.html

2. http://www.who.int/healthinfo/global_burden_disease/en/

3. Advanced trauma life support: ATLS student course manual. Chicago, IL: American College of Surgeons; (2012) J Trauma Acute Care Surg 74: 1363-1366. [Crossref]

4. Carney M, Ravin CE (1979) Intercostal Artery Laceration During Thoracocentesis. Chest 75: 520-522. [Crossref]

5. Yacovone ML, Kartan R, Bautista M (2011) Intercostal Artery Laceration Following Thoracentesis. Respir Care 55: 1495-1498. [Crossref]

6. Psallidas I, Helm EJ, Maskell NA, Yarmus L, Feller-Kopman DJ, et al. (2015) Iatrogenic injury to the intercostal artery: aetiology, diagnosis and therapeutic intervention. Thorax 70: 802-804

7. Rawlins R, Brown C, Carr C, Cameron C (2003) Life threatening haemorrhage after anterior needle aspiration of pneumothoraces. A role for lateral needle aspiration in emergency decompression of spontaneous pneumothorax. Emerg Med J 20: 383-384. [Crossref]

8. Butler KL, Best IM, Weaver WL, Bumpers HL (2003) Pulmonary Artery Injury and Cardiac Tamponade after Needle Decompression of a Suspected Tension Pneumothorax. J Trauma 54: 610-611. [Crossref]

9. Akoglu H, Akoglu EU, Evman S, Akoglu T, Altinok AD, et al. (2013) Determination of the appropriate catheter length and place for needle thoracostomy by using computed tomography scans of pneumothorax patients. Injury 44:1177-1182. [Crossref]

10. Inaba K, Branco BC, Eckstein M, Shatz DV, Martin MJ, et al (2011) Optimal positioning for emergent needle thoracostomy: a cadaver-based study. J Trauma 71:1099-1103. [Crossref]

11. Chang SJ, Ross SW, Kiefer DJ, Anderson WE, Rogers AT, et al. (2014) Evaluation of $8.0-\mathrm{cm}$ needle at the fourth anterior axillary line for needle chest decom- pression of tension pneumothorax. J Trauma Acute Care Surg 76:1029-1034. [Crossref]

12. Wax DB, Leibowitz AB (2007) Radiologic assessment of potential sites for needle decompression of a tension pneumothorax. Anesth Analg 105:1385-8. [Crossref]

13. Lamblin A, Turc J, Bylicki O, Lohe' as D, Martinez J-Y, et al. (2014) Measure of chest wall thickness in French soldiers: which technique to use for needle decompression of tension pneumothorax at the front? Mil Med 179:783-786. [Crossref]

14. Ferrie EP, Collum N, McGovern S (2005) The right place in the right space? Awareness of site for needle thoracocentesis. Emerg Med J 22:788-789. [Crossref]

15. Givens ML, Ayotte K, Manifold C (2014) Needle thoracostomy: implications of computed tomography chest wall thickness. Acad Emerg Med 11:211-213. [Crossref]

16. Harcke HT, Pearse LA, Levy AD, Getz JM, Robinson SR [2007] Chest wall thickness in military personnel: implications for needle thoracentesis in tension pneumothorax. Mil Med 172:1260-1263. [Crossref]

17. Powers WF, Clancy TV, Adams A, West TC, Kotwall CA, et al. (2014) Proper catheter selection for needle thoracostomy: a height and weight-based criteria. Injury 45:107111. [Crossref]

18. Sanchez LD, Straszewski S, Saghir A, Khan A, Horn E, et al. (2011) Anterior versus lateral needle decompression of tension pneumothorax: comparison by computed tomography chest wall measurement. Acad Emerg Med 18:1022-1026. [Crossref] 
19. Schroeder E, Valdez C, Krauthamer A, Khati N, Rasmus J, et al. (2013) Average chest wall thickness at two anatomic locations in trauma patients. Injury 44:1183-5. [Crossref]

20. Inaba K, Ives C, Mcclure K, Branco BC, Eckstein M, et al. (2012) Radiologic Evaluation of Alternative Sites for Needle Decompression of Tension Pneumothorax. Arch Surg 147: 813-818. [Crossref]

21. Kaserer A, Stein P, Simmen HP, Spahn DR, Neuhaus V (2017) Failure rate of prehospital chest decompression after severe thoracic trauma. Ame J Emer Med 35: 469-474.

22. Evans CC, Petersen A, Meier EN, Buick JE, Schreiber Met al. (2016) Resuscitation Outcomes Consortium Investigators. Prehospital traumatic cardiac arrest: Management and outcomes from the resuscitation outcomes consortium epistry-trauma and PROPHET registries. J Trauma Acute Care Surg 81: 285-293. [Crossref]

23. Miller AC, Harvey JE. Guidelines for the management of spontaneous pneumothorax Standards of Care Committee, British Thoracic Society. BMJ 307: 114-116. [Crossref]
24. Defense Health Board (2012) Needle Decompression of Tension Pneumothorax Tactical Combat Casualty Care Guideline Recommendations 2012-05. J Special Op Med 12: 118-122.

25. Chang SJ, Ross SW, Kiefer DJ, Anderson WE, Rogers AT, et al. (2014) Evaluation of $8.0-\mathrm{cm}$ needle at the fourth anterior axillary line for needle chest decompression of tension pneumothorax. J Trauma Acute Care Surg 76:1029-1034. [Crossref]

26. Beckett A, Savage E, Pannell D, Acharya S, Kirkpatrick A, et al. (2011) Needle Decompression for Tension Pneumothorax in Tactical Combat Casualty Care: Do Catheters Placed in the Midaxillary Line Kink More Often Than Those in the Midclavicular Line? J Trauma 71: S408-S412. [Crossref]

27. Chan SSW (2009) Tension Pneumothorax Managed Without Immediate Needle Decompression. The Journal of Emergency Medicine. 36: 242-245. [Crossref]

28. Moore KL, Agur AM. Essential Clinical Anatomy. Lippincott Williams \& Wilkins; 2014.

Copyright: (C2018 Gatz JD. This is an open-access article distributed under the terms of the Creative Commons Attribution License, which permits unrestricted use, distribution, and reproduction in any medium, provided the original author and source are credited. 